\title{
Ionic liquids as a neat lubricant applied to steel-steel contacts
}

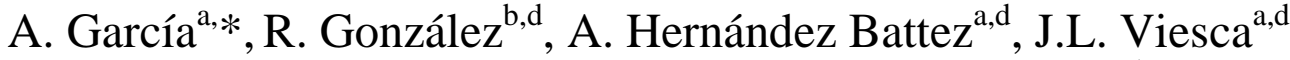 \\ R. Monge ${ }^{\mathrm{a}}$, A. Fernández-González ${ }^{\mathrm{c}}$, M. Hadfield ${ }^{\mathrm{d}}$ \\ ${ }^{a}$ Department of Construction and Manufacturing Engineering, University of Oviedo, Asturias, Spain \\ (*) Email: garciamaralberto@ uniovi.es \\ ${ }^{\mathrm{b}}$ Department of Marine Science and Technology, University of Oviedo, Asturias, Spain \\ ${ }^{\mathrm{c}}$ Department of Physical and Analytical Chemistry, University of Oviedo, Asturias, Spain \\ ${ }^{\mathrm{d}}$ School of Design, Engineering and Computing, Bournemouth University, UK
}

\begin{abstract}
This paper studies the use of 3 ionic liquids ([(NEMM)MOE][FAP], [BMP][FAP] and [BMP][NTf 2$]$ ) as neat lubricant within steel-steel contact conditions. Tribological tests (at 40 and $100^{\circ} \mathrm{C}$ ) were conducted in a HFRR tribometer and hence a complementary study was developed using a MTM tribometer. The wear surface on the discs was measured after the HFRR tests by confocal microscopy and also analyzed by SEM and XPS. The [BMP][NTf ${ }_{2}$ ] showed the lowest friction coefficient in the MTM and HFRR tests at $40^{\circ} \mathrm{C}$ but at $100^{\circ} \mathrm{C}$ its tribological behavior worsened due to its lowest viscosity. Similar results were found for wear behavior. Both antifriction and antiwear results were related to the tribofilms formation from the ECR and XPS measurements.
\end{abstract}

Keywords: ionic liquids, lubrication, wear, friction coefficient

\section{Introduction}

Since 2001 several papers have been published that investigate the potential use of ionic liquids (ILs) for lubrication. Most of this work has been focused on using ILs as base stock or as a pure lubricant [1]. Ionic liquids have some high performance properties for lubrication such as non-flammability, nonvolatility, high ionic conductivity, high thermo-oxidative stability and miscibility with organic compounds [2-4]. Due to the high temperature properties of the ionic liquids, they can be used as a pure lubricant under severe tribological conditions for which conventional lubricants do not perform well [57].

In addition, the advantages of using ILs as additives and their interaction with the wear surfaces have been studied by numerous authors $[2,8,9]$. Most of the early researches in the use of IL as lubricants has been focused on the use of $\mathrm{PF}_{6}$ and $\mathrm{BF}_{4}$ imidazolium salts [10,11]. However, the presence of these anions can produce unfavorable chemical reactions of the IL with water and lead to the formation of hydrogen fluoride, which can damage tribology systems [12]. For these reasons, several authors are focused on the research with hydrophobic ILs. Among the hydrophobic ILs can be found those based on the anions bis(trifluoromethylsulfonyl)imide [NTf 2 and tris(pentafluoroethyl)trifluorophosphate [FAP]. These ILs combine their higher hydrophobicity with their excellent hydrolytic stability [13]. Taking into account that fact, Gonzalez et al. studied the use of the ionic liquid 1-Butyl-1-methylpyrrolidinium 
tris(pentafluoroethyl)trifluorophosphate ([BMP][FAP]) as neat lubricant and as additive in the lubrication of conventional PVD coatings (CrN, TiN and DLC) [14]. Blanco et al. used ethyl-dimethyl-2methoxyethylammoniumtris(pentafluoroethyl)trifluorophosphate ([(NEMM)MOE][FAP]) as base oil additive in the lubrication of TiN and CrN PVD coatings $[15,16]$

The tribological behaviour of ionic liquids as neat lubricants or as additives has been evaluated for different types of contact, with steel-steel being the most studied case [17-21]. Now, this paper studies the use of three ionic liquids based on the $[\mathrm{FAP}]$ and $\left[\mathrm{NTf}_{2}\right]$ anions as neat lubricant applied to steelsteel contacts.

\section{Experimental details}

The properties of the ionic liquids used as lubricants in this study are listed in Table 1 . The viscosity of the ionic liquid at high shear rates $\left(10^{6}-10^{7} \mathrm{~s}^{-1}\right)$ and temperatures of 70 and $100^{\circ} \mathrm{C}$ was measured using an Ultra Shear Viscometer (PCS Instruments, UK), because of typical shear rates in the boundary lubrication regime reach values greater than $10^{6} \mathrm{~s}^{-1}$. The tribological tests conducted using the high frequency reciprocating rig (HFRR) (PCS Instruments, UK) considered the typical specimens: AISI 52100 steel balls (with $6.0 \mathrm{~mm}$ diameter, 58-66 HRC of hardness and less than $0.05 \mu \mathrm{m}$ of roughness) and softer AISI 52100 steel discs $\left(190-210 \mathrm{HV}_{30}\right.$ and roughness of less than $\left.0.02 \mu \mathrm{m}\right)$. The HFRR is a reciprocating friction and wear test machine which provides reliable assessment of the tribological behavior of lubricants and additives under a wide range of load, stroke length, frequency and temperature values. Such experiments were developed at a normal load of $7.85 \mathrm{~N}$ (corresponding to a maximum contact pressure of $1.31 \mathrm{GPa}$ ) under fully flooded lubrication, a stroke length of $2 \mathrm{~mm}$, a frequency of $25 \mathrm{~Hz}$, and duration of 60 minutes (corresponding to a sliding distance of $360 \mathrm{~m}$ ). The ionic liquid temperature was controlled and these experiments were conducted at temperatures of 40 and $100^{\circ} \mathrm{C}$. Friction force and electrical contact resistance (ECR) in order to determine the tribofilms formation on the wear surfaces were measured during the tribological tests. Each tribological test was repeated at least three times. The wear scar volume on the disc surface was measured after each test using confocal microscopy methodology. Tested surfaces were also analyzed by SEM and XPS in order to determine their chemical composition and the dominant wear mechanism.

Before the experiments using the HFRR tribometer, the ionic liquids were tested in a Mini Traction Machine (MTM) from PCS Instruments Ltd. in order to obtain their tribological behaviour under different 
contact conditions. The MTM is a tribometer with a ball-on-disc configuration where the antifriction and conditions. Both the disc and the ball are driven independently providing slide-roll ratios (SRR) from $0 \%$ (pure rolling) to $200 \%$ (pure sliding). Such tests were performed at room temperatures using $0.25 \mathrm{ml}$ of ionic liquid in the contact between the ball (AISI 52100, $18 \mathrm{~mm}$. diameter, $\mathrm{R}_{\mathrm{a}}<0.01 \mu \mathrm{m}$ ) and the disc (AISI 52100, $46 \mathrm{~mm}$. diameter, $\mathrm{R}_{\mathrm{a}}<0.01 \mu \mathrm{m}$ ), at normal load of $50 \mathrm{~N}$ (corresponding to a maximum contact pressure of $1.13 \mathrm{GPa}$ ), at sliding-rolling ratio of $50 \%$, and rolling speed from 3 to $200 \mathrm{~mm} / \mathrm{s}$.

\section{Results and discussion}

The results obtained from the experiments conducted using the MTM at room temperature, Fig. 1, showed clearly that under favorable contact conditions (higher rolling speed in this case) the $[\mathrm{BMP}]\left[\mathrm{NTf}_{2}\right]$ ionic liquid performs better. However, its tribological behaviour become worse more rapidly than the FAP-based ionic liquids when the rolling speed decreases. This tribological behaviour is related not only to the balance of formation/destruction of the tribofilms on the wear scar surface but also to the rheological behavior of the ionic liquids. It is noted that $[\mathrm{BMP}]\left[\mathrm{NTf}_{2}\right]$ ionic liquid has lower viscosity than the other ionic liquids for both tested temperatures, Fig. 2.

The results of the experiments conducted at $40^{\circ} \mathrm{C}$ using the HFRR machine showed that the lowest friction coefficient values was reached with the $[\mathrm{BMP}]\left[\mathrm{NTf}_{2}\right]$ ionic liquid, while the FAP-based ionic liquids presented similar friction coefficient values being slightly better the [BMP][FAP], shown as Fig. 3. Simultaneously, the electrical contact resistance (ECR) was measured during the friction and wear tests confirming the tribofilms formation in all cases.

Some tribological changes were detected during tests made at $100^{\circ} \mathrm{C}$, Fig. 4 . Now, the tribofilms formation in the tests with $[\mathrm{BMP}]\left[\mathrm{NTf}_{2}\right]$ was almost null and hence the increase in the friction coefficient. The FAP-based ionic liquids with similar tribofilms formation showed close friction coefficient values. This change with temperature for the tribological behavior of the $[\mathrm{BMP}]\left[\mathrm{NTf}_{2}\right]$ was analysed more in detail using the XPS technique.

Fig. 5 shows the average friction coefficient of all testing conditions performed in the HFRR machine. In general the friction coefficient rises with temperature. It is of interest to note the sharply increase of friction coefficient showed by $[\mathrm{BMP}]\left[\mathrm{NTf}_{2}\right]$ from 40 to $100^{\circ} \mathrm{C}$. 
Figs. 6, 7 and 8 show the wear behavior found in the tests at both temperatures. It can be observed that $[\mathrm{BMP}][\mathrm{FAP}]$ and $[\mathrm{BMP}]\left[\mathrm{NTf}_{2}\right]$ were similar (Figs. 6 and 8$)$ and lower than the $[(\mathrm{NEMM}) \mathrm{MOE}][\mathrm{FAP}]$ values but the SEM image of the base of the wear track show identical wear behavior in all cases. At $100^{\circ} \mathrm{C}$ the situation changed and the $[\mathrm{BMP}]\left[\mathrm{NTf}_{2}\right]$ ionic liquid showed poor wear behavior not only in quantity but also showing abrasive wear which can be observed in the SEM images, Figs. 7-8.

X-Ray photoelectron analysis was performed using a Phoibos hemispherical detector MDA5 from SPECS, using Mg x-ray radiation (1253.6 eV) at $13 \mathrm{kV}$ and $200 \mathrm{~W}$. High resolution measurements were recorded at constant pass energy $30 \mathrm{eV}$ with an energy step $0.1 \mathrm{eV}$. Spatial resolution was achieved using a $2.5 \mathrm{~mm}$ iris between the sample and the detector. Pressure in the analysis chamber was kept below $5 \cdot 10^{-9}$ mbar during the measurements. Analysis of the spectra was recorded using CasaXPS software as well as fitting software developed by the authors. Calibration of spectra was performed using the peak of adventitious $\mathrm{C} 1 \mathrm{~s}$ at $284.6 \mathrm{eV}$.

In Fig. 9 can be seen that samples lubricated with [(NEMM)MOE][FAP] at $40^{\circ} \mathrm{C}$ presents two XPS F1s bands inside the wear scar, one assignable to [FAP'] anion at $688.6 \mathrm{eV}(47 \%)$ and a second one at 687.5 $\mathrm{eV}(53 \%)$ related to fluoride-metal interaction due to chemical reaction between the ionic liquid and the surface [14]. When the sample is analysed outside the wear scar, only the peak corresponding to [FAP'] can be observed, as there is no chemical reaction between the ionic liquid and the surface (tribofilm). The situation remains very similar when the test temperature increased to $100^{\circ} \mathrm{C}$ both inside the wear scar with two F1s peaks at $687.5 \mathrm{eV}(56 \%$, fluoride-metal) and $688.6 \mathrm{eV}(44 \%$, [FAP $])$, and outside the wear scar with a single peak at $688.0 \mathrm{eV}$ belonging to unreacted [FAP'], see Fig. 10 and Table 2.

The sample lubricated with [BMP][FAP] behaves very similarly to that with [(NEMM)MOE][FAP]. At $40^{\circ} \mathrm{C}, \mathrm{F} 1 \mathrm{~s}$ photoelectron band inside the wear scar can be splitted into a [FAP $]$ band at $688.5 \mathrm{eV}(85 \%)$ and a F-metal interaction band at $686.6 \mathrm{eV}(15 \%)$ whereas outside the wear scar only the [FAP'] F1s photoelectron band can be observed at $688.2 \mathrm{eV}$. When temperature increased to $100^{\circ} \mathrm{C}$ the situation is practically the same than at $40^{\circ} \mathrm{C}$ : two bands inside the wear scar ([FAP $]$ at $688.6 \mathrm{eV}, 80 \%$, and fluorinemetal interaction at $687.0 \mathrm{eV}, 20 \%$ ) but only [FAP'] was found in the analysis of the outer part of the wear scar (688.4 eV) (Table 2).

Samples lubricated with [BMP] $\left[\mathrm{NTf}_{2}\right]$ do not show qualitative differences at $40^{\circ} \mathrm{C}$ or $100^{\circ} \mathrm{C}$ in $\mathrm{F} 1 \mathrm{~s}$ photoelectron bands. F1s band appears between $689.0 \mathrm{eV}$ and $689.2 \mathrm{eV}$ in any case (both temperatures, 
inside and outside, Fig.11, Table 2), matching the F1s band of the $\left[\mathrm{NTf}_{2}{ }^{-}\right]$anion as described by Bovio et al. [22].

The presence of neat $[\mathrm{BMP}]\left[\mathrm{NTf}_{2}\right]$ can be also detected inside and outside the wear scar at both $40^{\circ} \mathrm{C}$ and $100^{\circ} \mathrm{C}$ analysing the N1s photoelectron band. Pyrrolidinium based ionic liquids shows two N1s bands at $399.5 \mathrm{eV}$ from the $\left[\mathrm{NTf}_{2}^{-}\right]$anion and at $403 \mathrm{eV}$ from the pyrrolidinium cation [23] which are clearly seen in our case as reflected in Fig. 12.

Nevertheless, O1s band shows an interesting behaviour in these samples. Three different O1s bands can be detected at $40^{\circ} \mathrm{C}$ inside the wear scar: $529.8 \mathrm{eV}$ (assignable to $\mathrm{Fe}_{2} \mathrm{O}_{3}$, [24]), $532.8 \mathrm{eV}$ (from the [ $\mathrm{NTf}_{2}{ }^{-}$] anion according to [22-23]) and 531.2 eV which probably arises from the tribofilm. Only two of these bands are present in the outer part of the wear scar $\left(530.1 \mathrm{eV}\right.$ from $\mathrm{Fe}_{2} \mathrm{O}_{3}$ and $532.7 \mathrm{eV}$ from the ionic liquid), although the band at $531.9 \mathrm{eV}$ due to the tribofilm is not present, as there is no tribofilm outside the wear scar (Fig. 13, Table 3).

When the test is performed at $100^{\circ} \mathrm{C}$, the situation in the outer part is very similar $(\mathrm{O} 1 \mathrm{~s}$ bands at $530.5 \mathrm{eV}$ and $532.8 \mathrm{eV}$ from iron oxides and neat $\left[\mathrm{NTf}_{2}^{-}\right]$) although inside the wear scar only neat ionic liquid can be detected at $532.8 \mathrm{eV}$ (Fig. 14, Table 3), confirming the inexistence of tribofilm as suggested by ECR measurements. According to the previously shown results, the tribofilm in the lubrication with $[\mathrm{BMP}]\left[\mathrm{NTf}_{2}\right]$ at $40^{\circ} \mathrm{C}$ does not seem to involve the anion as it happened with [BMP][FAP], but the ionic liquid seems to somehow induce the formation of the tribofilm while remaining chemically unaltered. $[\mathrm{BMP}]\left[\mathrm{NTf}_{2}\right]$ at $100^{\circ} \mathrm{C}$ does not create a tribofilm on the surface, thus increasing the friction coefficient. The presence of iron oxides was confirmed by checking the Fe2p3/2 photoelectron band inside the wear scar. Every sample shows a band between 709.9 and $710.4 \mathrm{eV}$ assignable to iron oxides [24] with the single exception of $[\mathrm{BMP}]\left[\mathrm{NTf}_{2}\right]$ at $100^{\circ} \mathrm{C}$.

Further XPS analysis concerning P and S elements was also carried out. As reflected in the following tables 4 and 5, [(NEMM)(MOE)][FAP] shows a clear P2p peak both at $40^{\circ} \mathrm{C}$ and $100^{\circ} \mathrm{C}$ around 133.6 which is a typical value for phosphates [25]. The behaviour of [BMP][FAP] is very similar, although the intensity of the $\mathrm{P} 2 \mathrm{p}$ peaks is lower. However, the intensity of $\mathrm{P} 2 \mathrm{p}$ in the case of $[\mathrm{BMP}]\left[\mathrm{NTf}_{2}\right]$ is negligible.

Analysis of S2p peak reveals a band at $169.3 \mathrm{eV}(\mathrm{FWHM} 2.8 \mathrm{eV})$ for [(NEMM)(MOE)][FAP] at $40^{\circ} \mathrm{C}$ which is almost the same than for $[(\mathrm{NEMM})(\mathrm{MOE})][\mathrm{FAP}]$ at $100^{\circ} \mathrm{C}(169.6 \mathrm{eV}(\mathrm{FWHM} 2.5 \mathrm{eV}))$ which is near the iron (III) sulfate band at $168.9 \mathrm{eV}[24,25]$. The situation is the same for [BMP][NTf $\left.{ }_{2}\right]$ with peaks 
at $169.2 \mathrm{eV}(\mathrm{FWHM} 2.5 \mathrm{eV})$ at $40^{\circ} \mathrm{C}$ and $169.2 \mathrm{eV}(\mathrm{FWHM} 2.8 \mathrm{eV})$ at $100^{\circ} \mathrm{C}$ suggesting also the presence of iron (III) sulfate. However, the intensity of S2p peak is very low in the case of [BMP][FAP] with a noisy peak at $169.4 \mathrm{eV}(\mathrm{FWHM} 2.4 \mathrm{eV})$ at $40^{\circ} \mathrm{C}$ which disappears when increasing the temperature at $100^{\circ} \mathrm{C}$ suggesting the disappearance of the iron (III) sulfate in the tribolayer.

\section{Conclusions}

This paper studied the use of ethyl-dimethyl-2-methoxyethylammonium tris(pentafluoroethyl)trifluorophosphate, 1-butyl-1-methylpyrrolidinium tris(pentafluoroethyl)trifluorophosphate and 1-butyl-1-methylpyrrolidinium bis(trifluoromethylsulfonyl) imide ionic liquids as neat lubricants within steel-steel contact. Results show that $[\mathrm{BMP}]\left[\mathrm{NTf}_{2}\right]$ ionic liquid exhibited the minimum friction coefficient for the HFRR tests conducted at $40^{\circ} \mathrm{C}$ and for MTM tests. For the two ionic liquids with the same [FAP] anion, the $[\mathrm{BMP}][\mathrm{FAP}]$ showed the better anti-friction performance for all the tests made, according with previous author's results related to these two ionic liquids ([BMP][FAP] and [(NEMM)MOE][FAP]) in the lubrication of PVD coatings. Nevertheless, $[\mathrm{BMP}]\left[\mathrm{NTf}_{2}\right]$ showed the highest friction coefficient in the HFRR tests made at $100^{\circ} \mathrm{C}$ according with its lowest viscosity value at this temperature.

Wear results exhibited similar behavior, showing the surfaces lubricated with $[\mathrm{BMP}]\left[\mathrm{NTf}_{2}\right]$ as the lowest wear volume for the tests made at $40^{\circ} \mathrm{C}$. However with the increasing temperature this ionic liquid worsened its anti-wear performance showing the higher wear track with an important surface damage. Wear volume measured after tests made with [BMP][FAP] and [(NEMM)MOE][FAP] were similar, although the former showed a slightly higher anti-wear behavior.

XPS confirmed the presence of tribofilms in samples lubricated with [BMP][FAP] or $[(\mathrm{NEMM}) \mathrm{MOE}][\mathrm{FAP}]$ both at $40^{\circ} \mathrm{C}$ and $100^{\circ} \mathrm{C}$ whereas only neat ionic liquid without interaction with the surface could be detected inside the wear scar of sample lubricated with $[\mathrm{BMP}]\left[\mathrm{NTf}_{2}\right]$ at $100^{\circ} \mathrm{C}$, thus confirming the evidences obtained through ECR.

\section{Acknowledgements}

The authors are grateful to the FICYT (the Foundation for the promotion in Asturias of the Applied Scientific Research and Technology) for supporting the research stay of the first author at Imperial College London (UK) and the Spanish Ministry of Science and Innovation for also supporting this paper within the framework of the Research Project WINDTRIB (DPI2010-18166). They also thank the 
Ministry of Education, Culture and Sport for funding, within the program "José Castillejo", the research stay of José Luis Viesca at Bournemouth University. In addition, we would like to thank the Unit for Molecular Spectroscopy and XPS from the Scientific-Technical Services of the University of Oviedo.

\section{References}

[1] Qu J, Bansal DG, Yu B, Howe, JY, Luo H, Dai S, et al. Antiwear Performance and Mechanism of an Oil-Miscible Ionic Liquid as a Lubricant Additive. ACS Appl. Mater. Interfaces 2012;4:997-1002.

[2] Minami I. Ionic Liquids in Tribology. Molecules 2009;14:2286-305.

[3] Jimenez AE, Bermudez MD. Imidazolium ionic liquids as additives of the synthetic ester propylene glycol dioleate in aluminium-steel lubrication. Wear 2008;265:787-98.

[4] Zhou F, Liang Y, Liu W. Ionic liquid lubricants: designed chemistry for engineering applications, Chemical Society Reviews 2009;28: 2590-9.

[5] Bermúdez MD, Jiménez AE, Sanes J, Carrión, FJ. Ionic Liquids as Advanced Lubricant Fluids. Molecules 2009;14:2888-908.

[6] Yao M, Fan M, Liang Y, Zhou F, Xia Y. Imidazolium hexafluorophospate ionic liquids as high temperature lubricants for steel-steel contacts. Wear 2010;268:67-71.

[7] Jiménez AE, Bermúdez MD, Iglesias P. Lubrication of Inconel 600 with ionic liquids at high temperature. Tribol Int 2009;42:1744-51.

[8] Liu W, Liang Y, Zhou F. Ionic liquid lubricants: designed chemistry for engineering applications. Chem Soc Rev 2009;38:2590-9.

[9] Jimenez AE, Bermudez MD, Carrion FJ, Martinez-Nicolas G. Room temperature ionic liquids as lubricant additives in steel-aluminium contacts: Influence of sliding velocity, normal load and temperature. Wear 2006;261:347-59.

[10] Battez AH, González R, Viesca JL, Blanco D, Asedegbega E, Osorio A. Tribological behavior of two imidazolium ionic liquids as lubricant additives for steel/steel contacts. Wear 2009;266:1224-8.

[11] Viesca JL, Battez AH, González R, Torres Pérez A, Reddyhoff T, Spikes HA. Assesing boundary film formation of lubricant additivised with 1-hexyl-3-methylimidazolium tetrafluoroborate using ECR as qualitive indicator. Wear 2010;269:112-7.

[12] Torimoto T, Tsuda T, Okazaki K, Kuwabata S. New Frontiers in Materials Science Opened by Ionic Liquids. Adv Mater 2010; 22:1196-221. 
[13] Gaciño FM, Regueira T, Lugo L, Comuñas MJP, Fernández F. Influence of Molecular Structure on

Densities and Viscosities of Several Ionic Liquids. J Chem Eng Data 2011;56:4984-99.

[14] Gonzalez R, Hernandez Battez A, Blanco D, Viesca JL, Fernández-González A. Lubrication of TiN, CrN and DLC PVD coatings with 1-Butyl-1-methylpyrrolidinium tris(pentafluoroethyl)trifluorophosphate. Tribol Lett 2010;40:269-77.

[15] Blanco D, Viesca JL, Hernandez Battez A, Gonzalez R, Fernández-González A. Lubrication of CrN Coating With Ethyl-Dimethyl-2-Methoxyethylammonium Tris(pentafluoroethyl)Trifluorophosphate Ionic Liquid as Additive to PAO 6. Tribol Lett 2011;41:295-302.

[16] Blanco D, Gonzalez R, Hernandez Battez A, Viesca JL, Fernández-González A. Use of ethyldimethyl-2-methoxyethylammoniumtris(pentafluoroethyl)trifluorophosphate as base oil additive in the lubrication of TiN PVD coating. Tribol Int 2011;44:645-50.

[17] Liu W, Ye C, Gong Q, Wang H, Wang P. Tribological performance of room-temperature ionic liquids as lubricant. Tribol Lett 2002;13:81-5.

[18] Lu Q, Wang H, Ye C, Liu W, Xue Q. Room temperature ionic liquid 1-ethyl-3hexylimidazoliumbis(trifluoromethylsulfonyl)-imide as lubricant for steel/steel contact. Tribol Int $2004 ; 37: 547-52$

[19] Sanes J, Carrion FJ, Bermudez MD, Martinez-Nicolas G. Ionic liquids as lubricants of polystyrene and polyamide 6-steel contacts. Preparation and properties of new polymer-ionic liquid dispersions. Tribol Lett 2006;21:121-33.

[20] Yao M, Liang Y, Xia Y, Zhou F. Bisimidazolium Ionic Liquids as the High-Performance Antiwear Additives in Poly (ethylene glycol) for Steel-Steel Contacts. ACS Appl Mater Interfaces 2009; $1: 467-71$.

[21] Palacio M, Bhushan B. A Review of Ionic Liquids for Green Molecular Lubrication in Nanotechnology. Tribol Lett 2010; 40:247-68.

[22] Bovio S, Podesta A, Lenardi C, Milani P. Evidence of Extended Solidlike Layering in [Bmim][NTf2] Ionic Liquid Thin Films at Room-Temperature. J Phys Chem B 2009;113:6600-3.

[23] Shuang M, Hurisso BB, Lovelock KRJ, Licence P. Does the influence of substituents impact upon the surface composition of pyrrolidinium-based ionic liquids? An angle resolved XPS study. Phys Chem Chem Phys 2012;14:5229-38. 
[24] Wagner CD, Riggs WM, Davis LE, Moulder JF. Handbook of X-Ray Photoelectron Spectroscopy. 1st ed. Eden Prairie: Perkin-Elmer Corporation; 1979.

[25] Mangolini F, Rossi A, Spencer N D. Chemical Reactivity of Triphenyl Phosphorothionate (TPPT) with Iron: An ATR/FT-IR and XPS Investigation. J. Phys. Chem. C 2011;115(4):1339-54. 


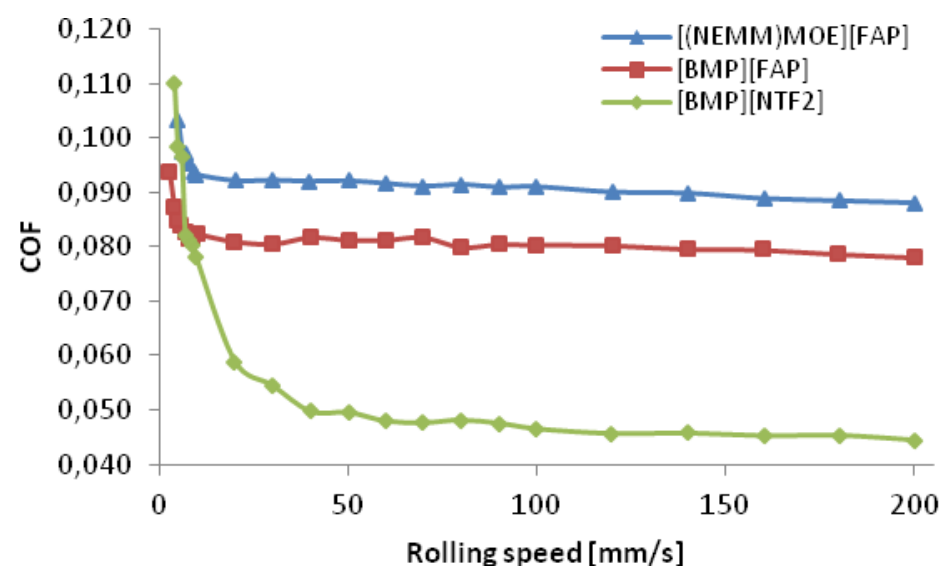

Fig. 1. Stribeck curves obtained at the MTM at normal load of $50 \mathrm{~N}$ and $50 \%$ of SRR. 

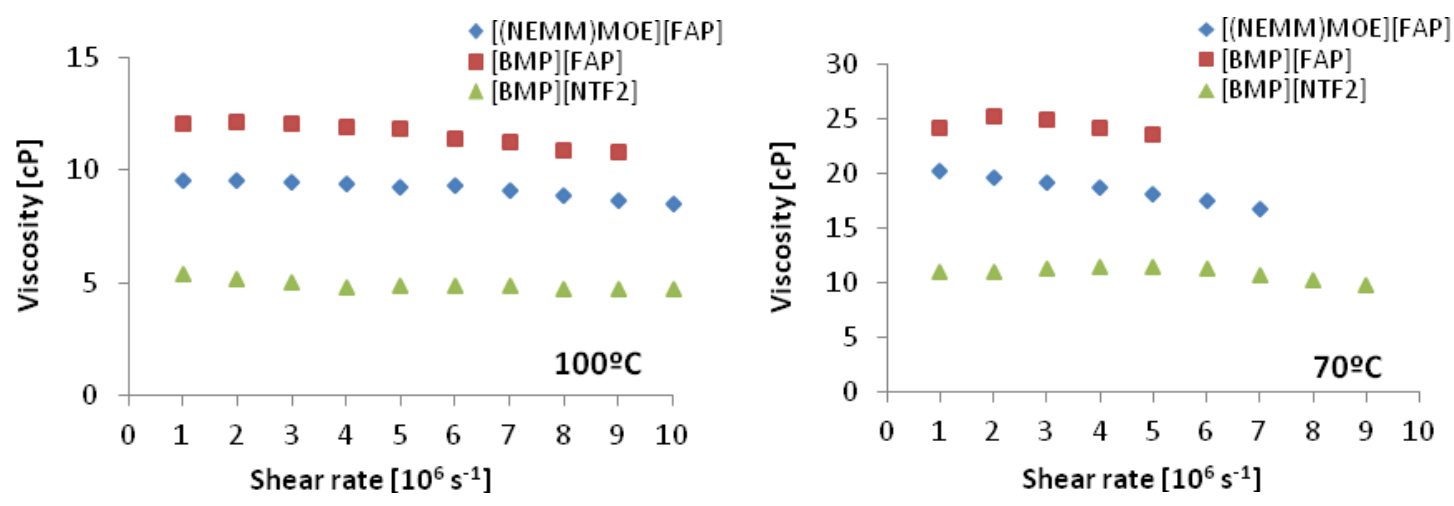

Fig. 2. Viscosity of IL's measured at high shear rates. 

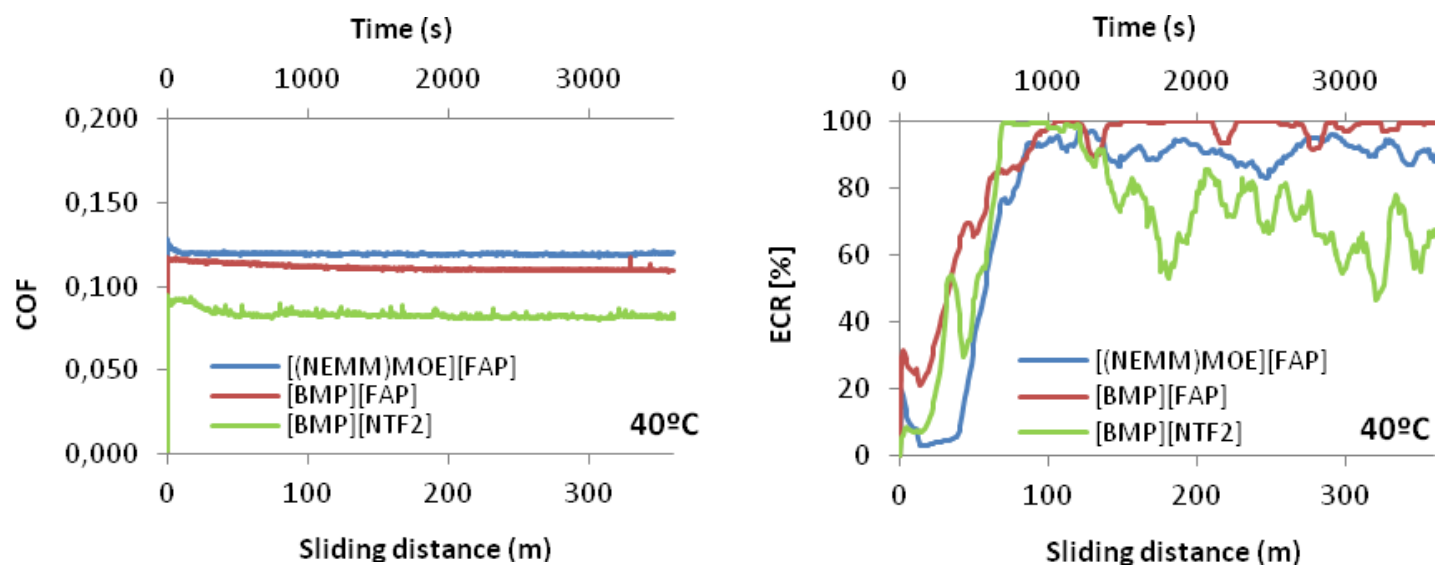

Fig. 3. Friction and ECR behavior for tests at $40^{\circ} \mathrm{C}$. 

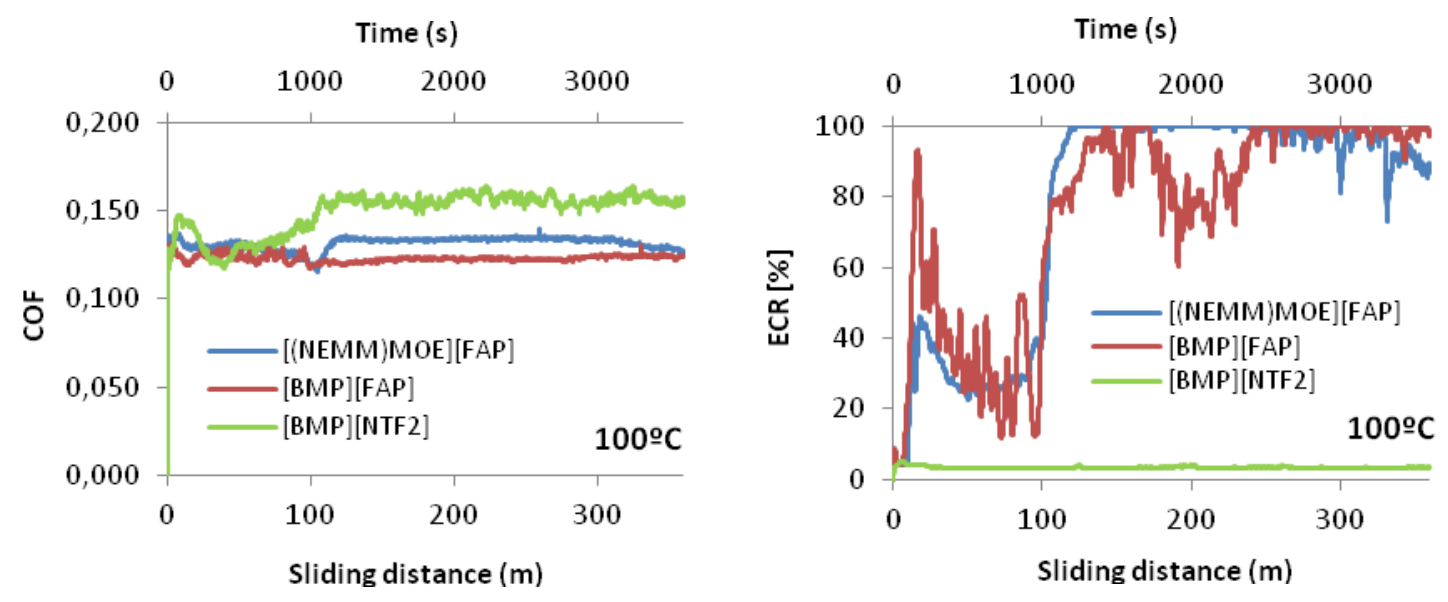

Fig. 4. Friction and ECR behavior for tests at $100^{\circ} \mathrm{C}$. 


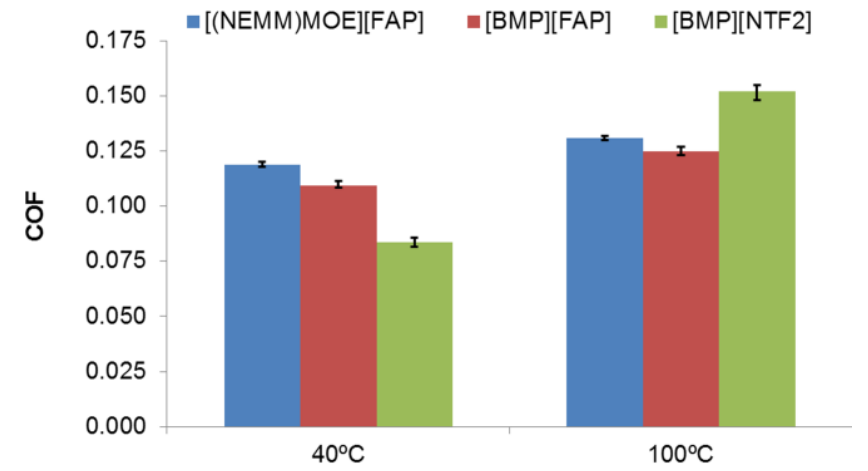

Fig. 5. Average friction coefficient from the reciprocating wear tests made in the HFRR machine. 

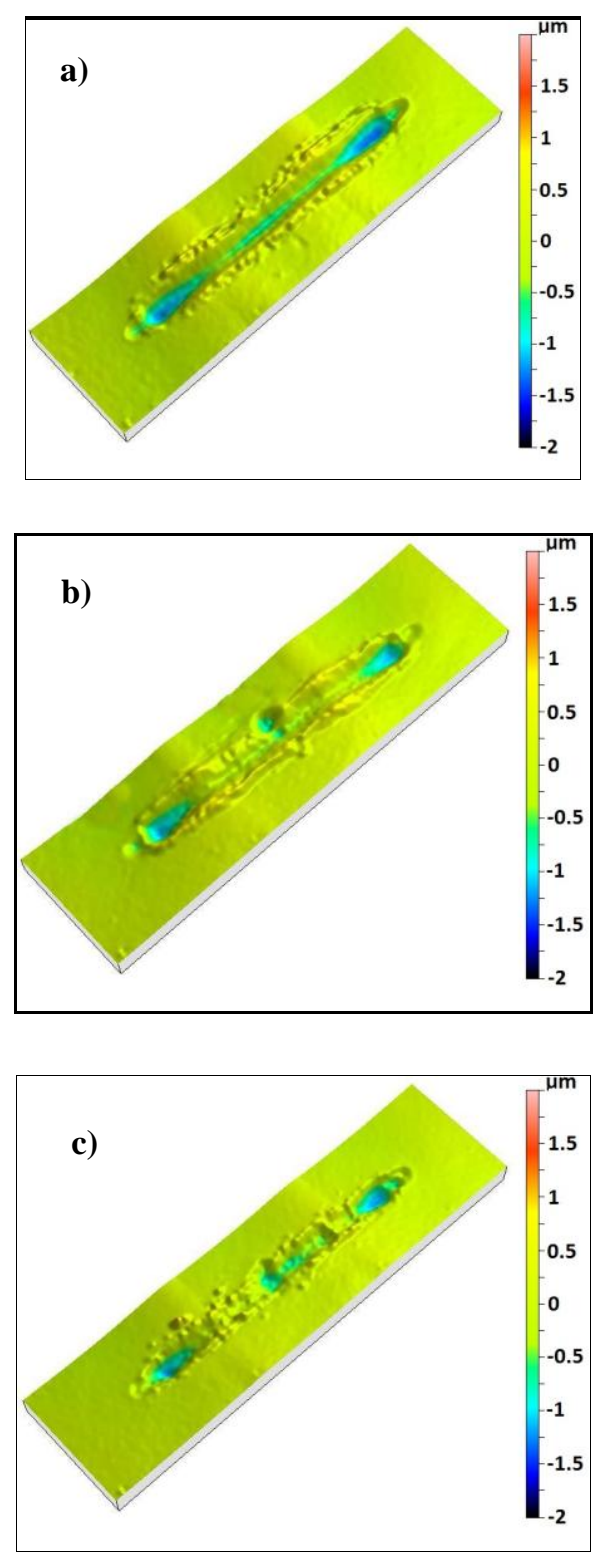
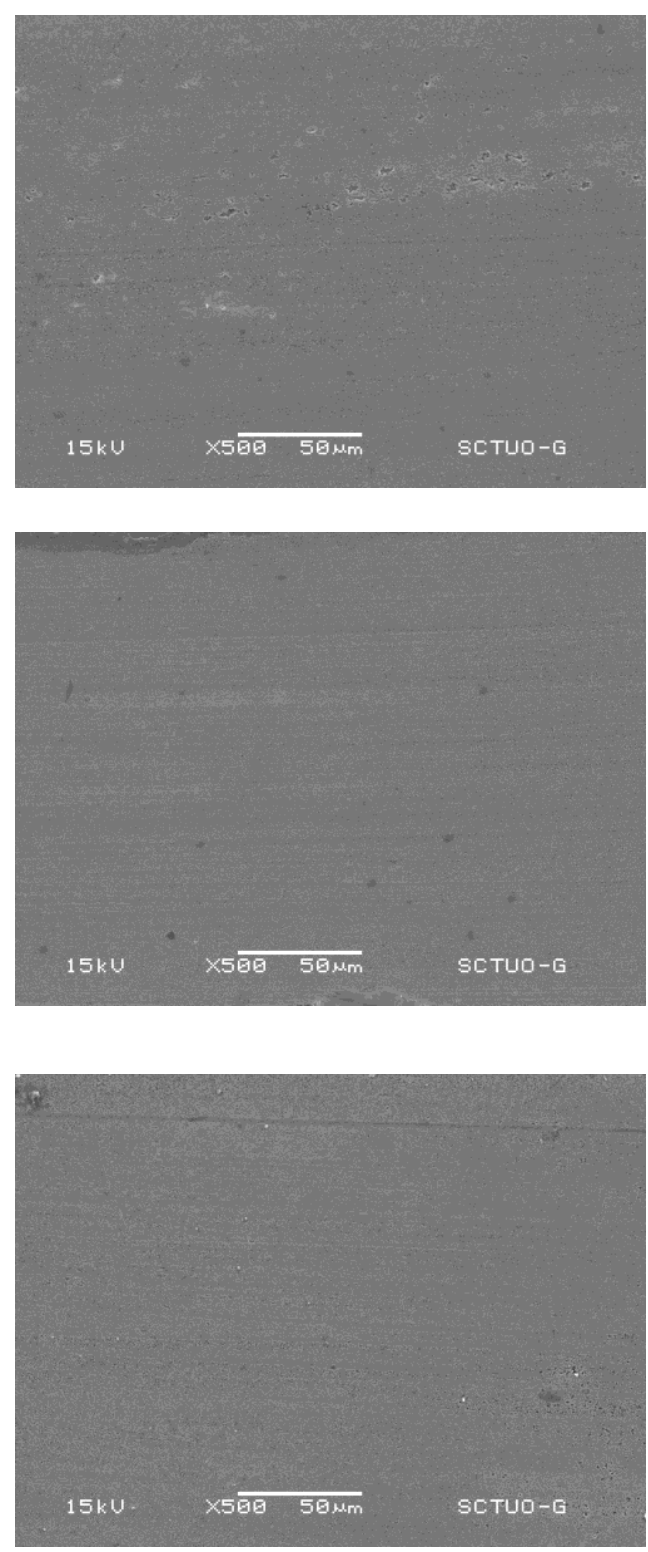

Fig. 6. 3D confocal reconstruction of wear track and SEM image of the bottom of wear track for test at $40^{\circ} \mathrm{C}$. a) $[(\mathrm{NEMM}) \mathrm{MOE}][\mathrm{FAP}]$; b) [BMP][FAP]; c) [BMP][NTf $\left.{ }_{2}\right]$ 

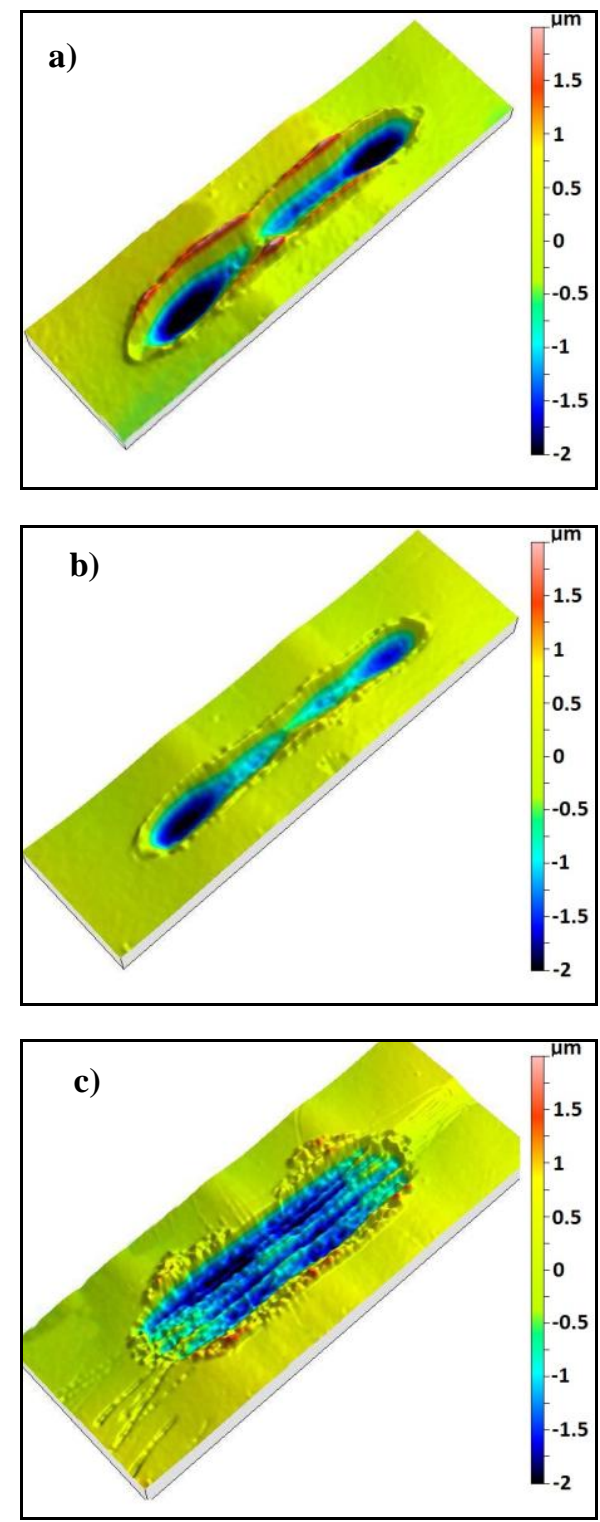
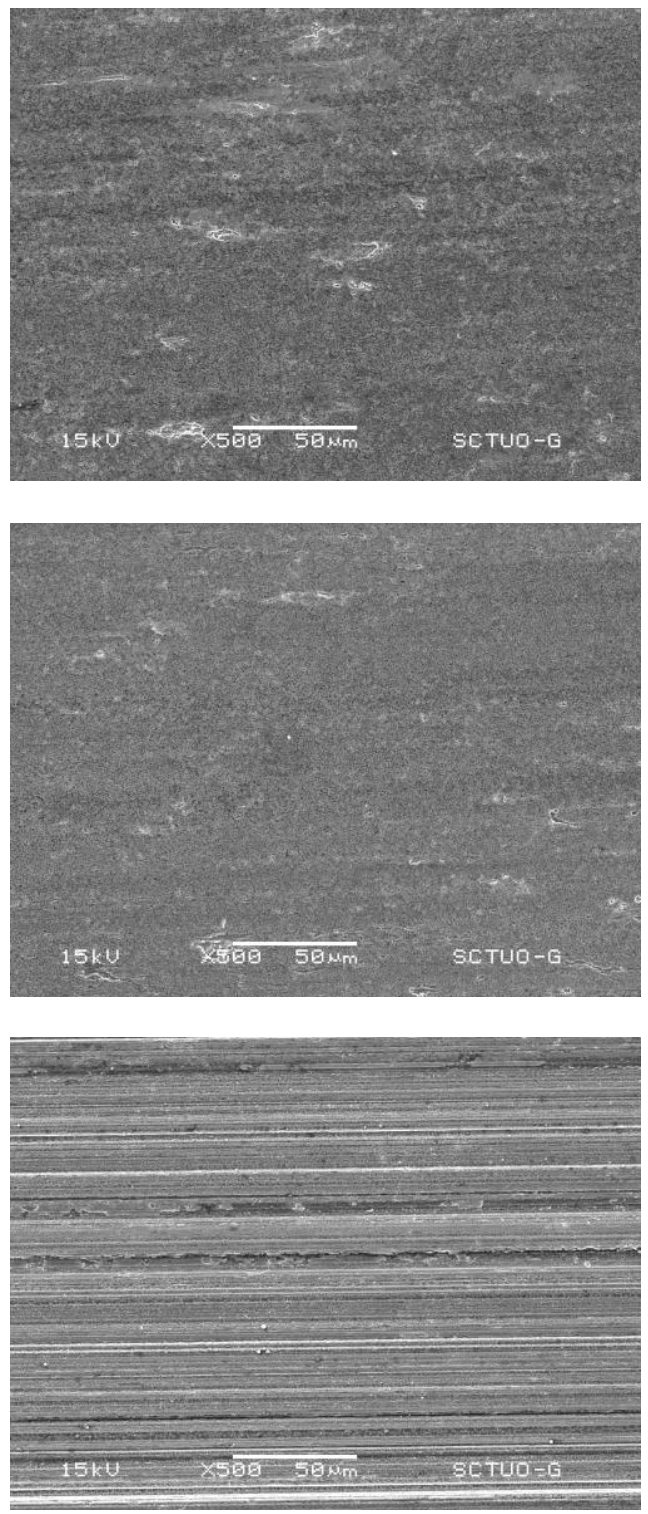

Fig. 7. 3D confocal reconstruction of wear track and SEM image of the bottom of wear track for test at $100^{\circ} \mathrm{C}$. a) [(NEMM)MOE][FAP]; b) [BMP][FAP]; c) [BMP][NTf $\left.{ }_{2}\right]$ 
Figure(s)

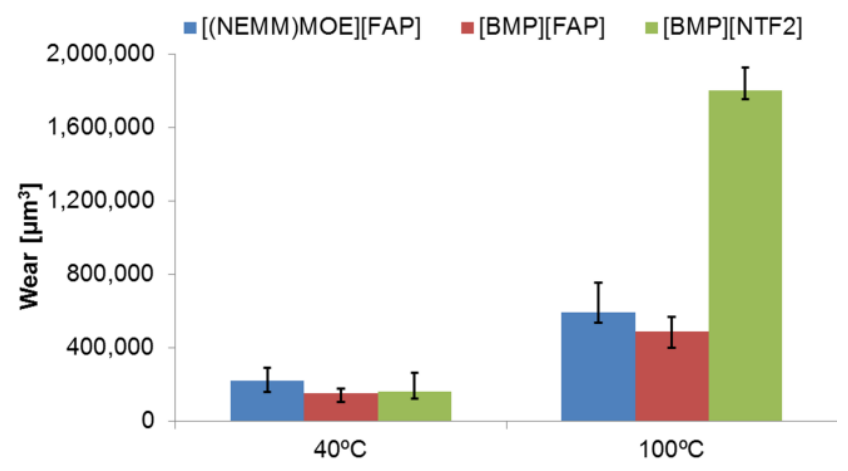

Fig. 8. Average wear volume. 

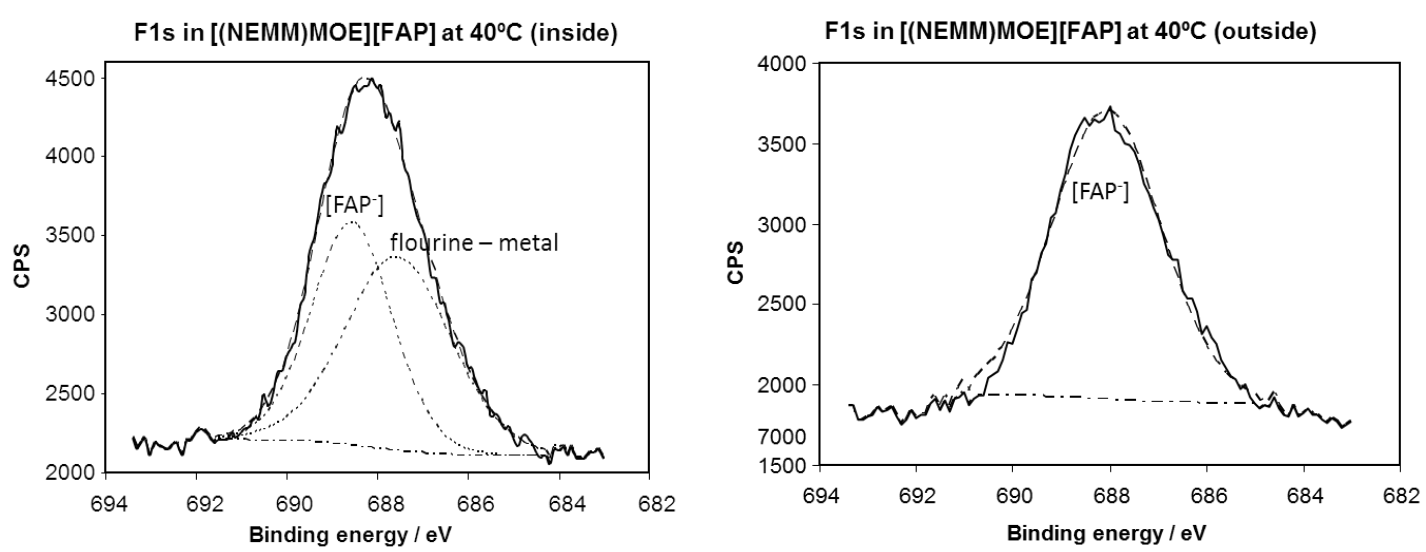

Fig. 9. F1s XPS spectra for [(NEMM)MOE][FAP] at $40^{\circ} \mathrm{C}$ (inside and outside the wear scar). 

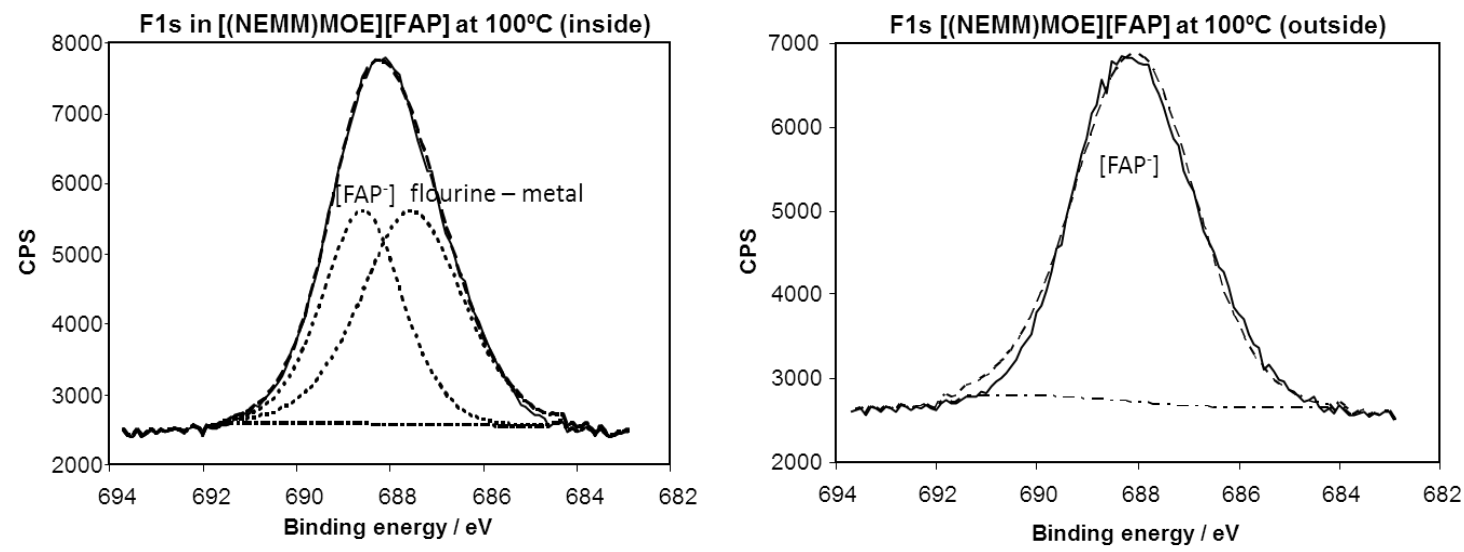

Fig. 10. F1s XPS spectra for [(NEMM)MOE][FAP] at $100^{\circ} \mathrm{C}$ (inside and outside the wear scar). 

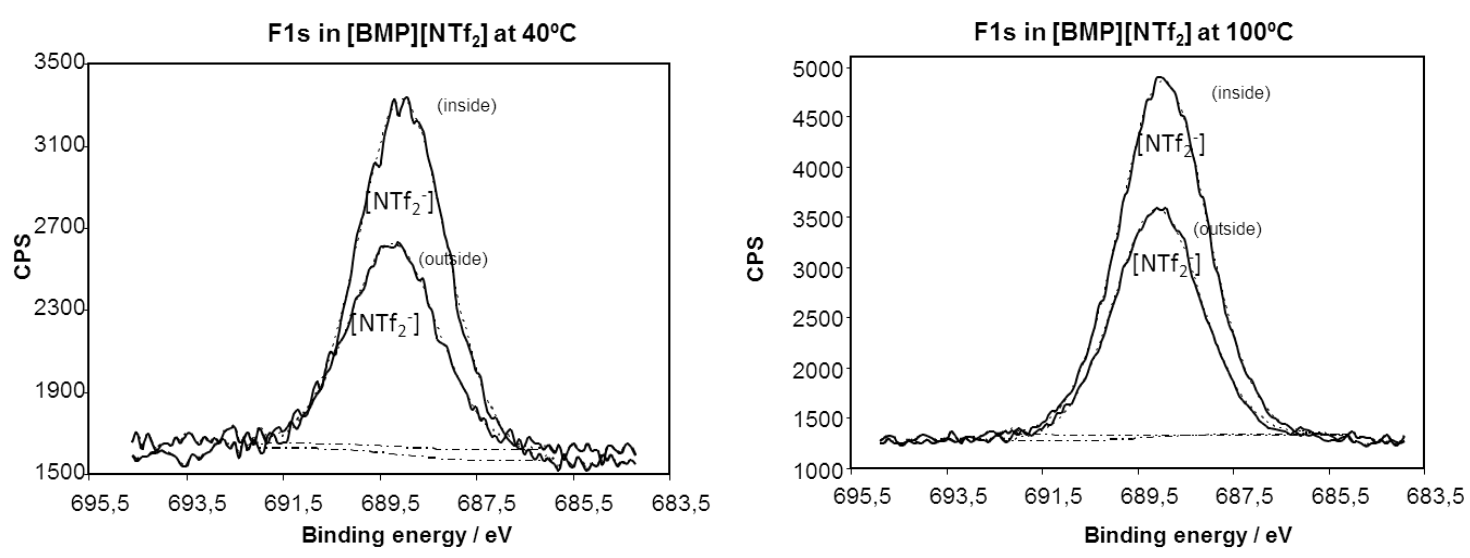

Fig. 11. F1s XPS spectra for $[\mathrm{BMP}]\left[\mathrm{NTf}_{2}\right]$ at $40^{\circ} \mathrm{C}$ and $100^{\circ} \mathrm{C}$ (outside and inside the wear scar). 

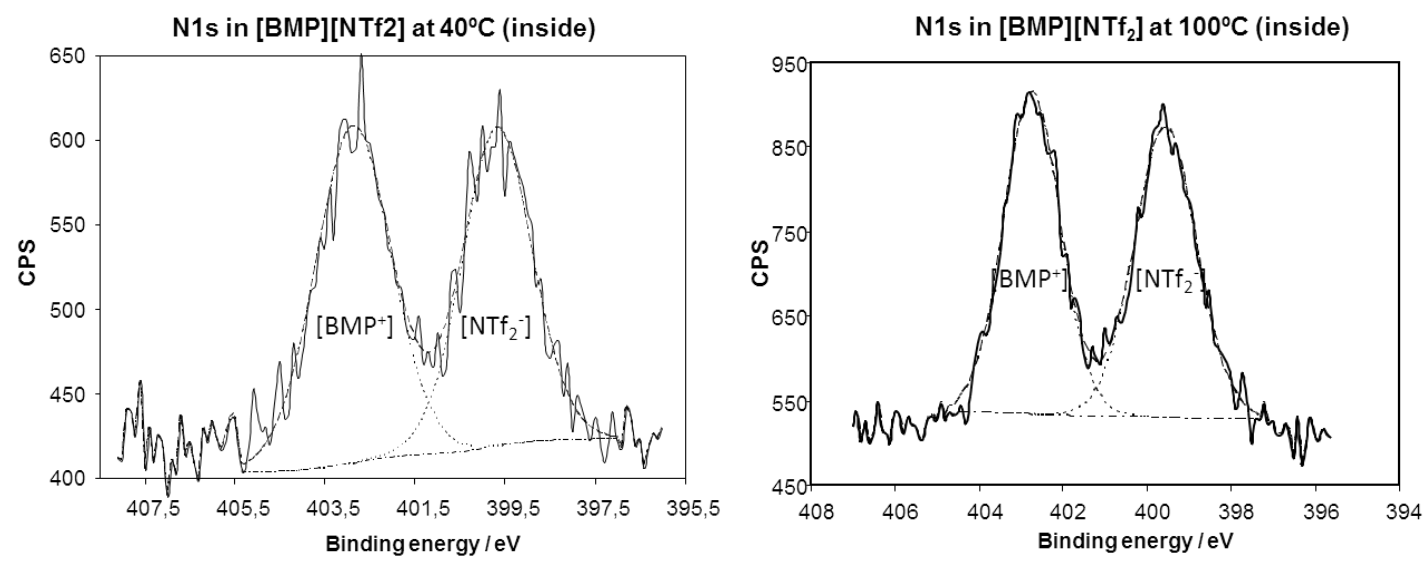

Fig. 12. N1s XPS spectra for $[\mathrm{BMP}]\left[\mathrm{NTf}_{2}\right]$ at $40^{\circ} \mathrm{C}$ and $100^{\circ} \mathrm{C}$ (inside the wear scar). 

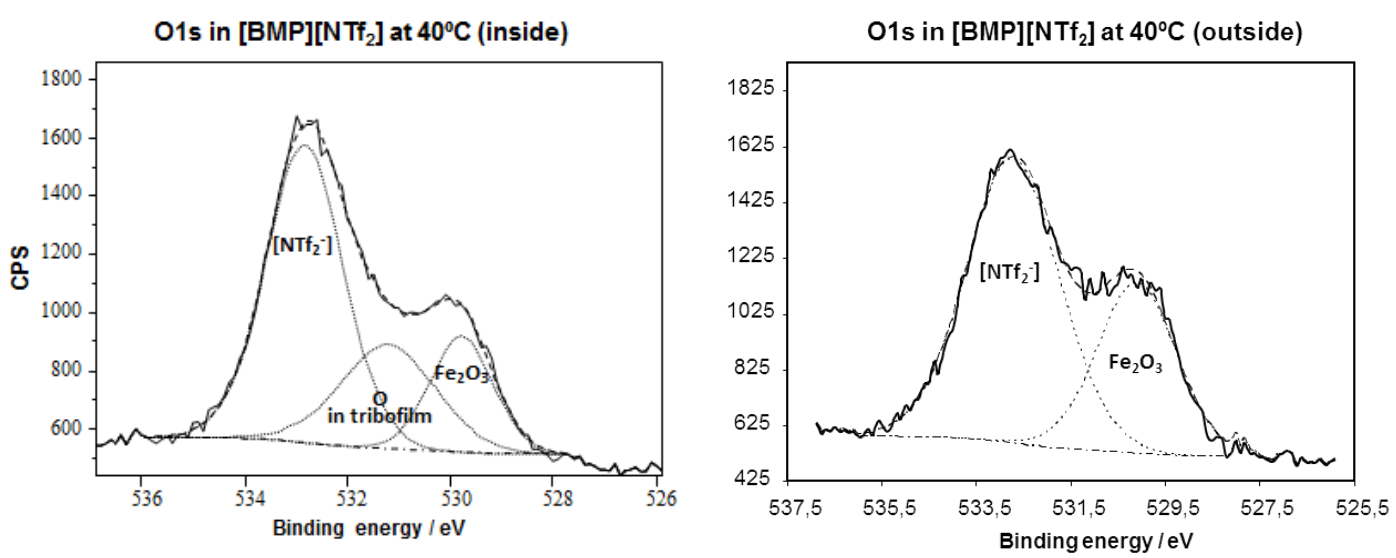

Fig. 13. O1s XPS spectra for [BMP][NTf $\left.{ }_{2}\right]$ at $40^{\circ} \mathrm{C}$ (inside and outside the wear scar). 

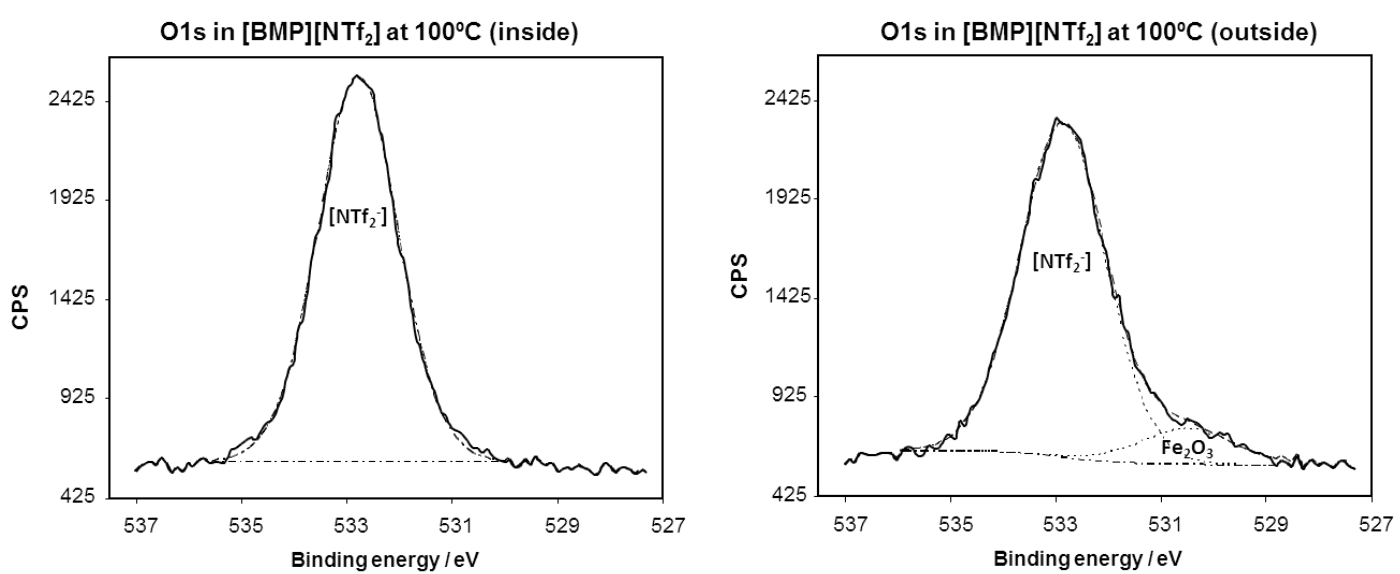

Fig. 14. O1s XPS spectra for $[\mathrm{BMP}]\left[\mathrm{NTf}_{2}\right]$ at $100^{\circ} \mathrm{C}$ (inside and outside the wear scar). 
Table 1. Ionic liquids properties.

\begin{tabular}{|c|c|c|c|c|c|c|c|}
\hline \multicolumn{2}{|l|}{ Ionic Liquids } & \multirow{3}{*}{ IUPAC name } & \multirow{3}{*}{$\begin{array}{l}\text { Purity } \\
(\%)\end{array}$} & \multirow{3}{*}{$\begin{array}{c}\text { Water content } \\
(\text { ppm) }\end{array}$} & \multirow{2}{*}{\multicolumn{2}{|c|}{ Viscosity $\left(\mathrm{mm}^{2} / \mathbf{s}\right)^{*}$}} & \multirow{3}{*}{$\begin{array}{c}\text { Viscosity } \\
\text { Index* }\end{array}$} \\
\hline \multirow[t]{2}{*}{ Cation } & \multirow[t]{2}{*}{ Anion } & & & & & & \\
\hline & & & & & $40^{\circ} \mathrm{C}$ & $100^{\circ} \mathrm{C}$ & \\
\hline [(NEMM)MOE] & {$[\mathrm{FAP}]$} & $\begin{array}{l}\text { ethyl-dimethyl-2- } \\
\text { methoxyethylammonium } \\
\text { tris(pentafluoroethyl)trifluorophosphate }\end{array}$ & $>99$ & $\begin{array}{c}<100 \\
\text { (Karl Fisher) }\end{array}$ & 38.652 & 6.550 & 123 \\
\hline$[\mathrm{BMP}]$ & {$[\mathrm{FAP}]$} & $\begin{array}{l}\text { 1-Butyl-1-methylpyrrolidinium } \\
\text { tris(pentafluoroethyl)trifluorophosphate }\end{array}$ & $>99$ & $<1 \%$ & 58.758 & 8.538 & 118 \\
\hline [BMP] & {$\left[\mathrm{NTf}_{2}\right]$} & $\begin{array}{l}\text { 1-Butyl-1-methylpyrrolidinium } \\
\text { bis(trifluoromethylsulfonyl)imide }\end{array}$ & $>99$ & $\begin{array}{c}<100 \\
\text { (Karl Fisher) }\end{array}$ & 28.826 & 6.228 & 174 \\
\hline
\end{tabular}

* Measured in a SVM 3000 Stabinger Viscometer (ASTM D7042, D2270)

Chemical structure

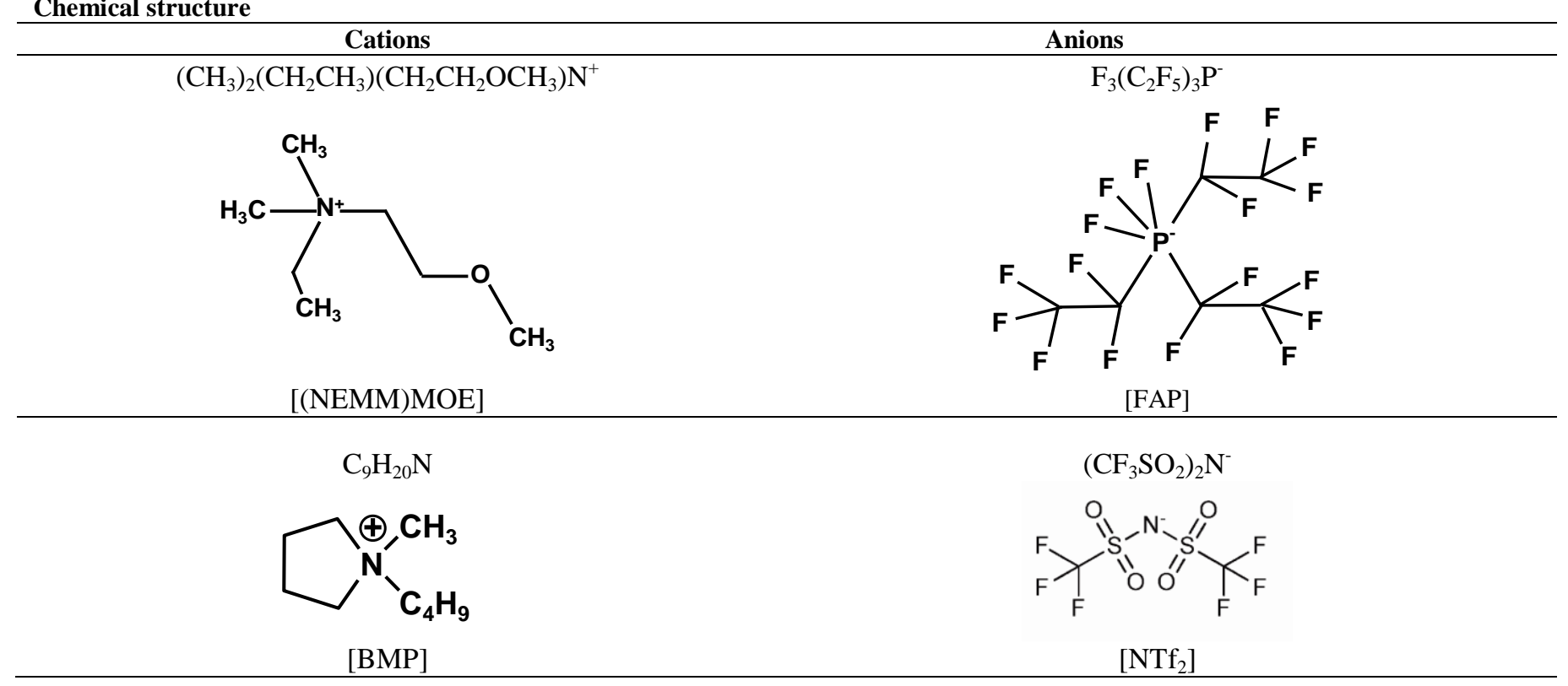


Table 2. F1s photoelectron band. FWHM is given in brackets.

\begin{tabular}{|c|c|c|c|}
\hline $\begin{array}{c}\text { F1s } \\
\text { (inside) }\end{array}$ & {$[(\mathbf{N E M M})(\mathrm{MOE})][$ FAP $]$} & {$[\mathbf{B M P}][\mathbf{F A P}]$} & {$[\mathrm{BMP}]\left[\mathbf{N T f}_{2}\right]$} \\
\hline $40^{\circ} \mathrm{C}$ & $\begin{array}{l}688.6(2.1) \text { eV } 47 \% \\
687.5(2.7) \text { eV } 53 \% \\
\end{array}$ & $\begin{array}{l}688.5(2.4) \mathrm{eV} 85 \% \\
686.6(2.1) \mathrm{eV} 15 \% \\
\end{array}$ & $689.0(2.1) \mathrm{eV}$ \\
\hline $100^{\circ} \mathrm{C}$ & $\begin{array}{l}687.5(2.5) \text { eV } 56 \% \\
688.6(2.0) \text { eV } 44 \% \\
\end{array}$ & $\begin{array}{l}688.6(2.2) \mathrm{eV} 80 \% \\
687.0(1.9) \mathrm{eV} 20 \% \\
\end{array}$ & $689.0(2.1) \mathrm{eV}$ \\
\hline $\begin{array}{c}\text { F1s } \\
\text { (outside) }\end{array}$ & {$[(\mathrm{NEMM})(\mathrm{MOE})][\mathrm{FAP}]$} & {$[\mathrm{BMP}][\mathbf{F A P}]$} & {$[\mathrm{BMP}]\left[\mathbf{N T f}_{2}\right]$} \\
\hline $40^{\circ} \mathrm{C}$ & $688.0(2.6) \mathrm{eV}$ & $688.2(2.7) \mathrm{eV}$ & $689.2(2.2) \mathrm{eV}$ \\
\hline $100^{\circ} \mathrm{C}$ & $688.0(2.8) \mathrm{eV}$ & $688.4(2.8) \mathrm{eV}$ & $689.1(2.1) \mathrm{eV}$ \\
\hline
\end{tabular}


Table 3. O1s photoelectron band. FWHM is given in brackets.

\begin{tabular}{|c|c|c|c|}
\hline $\begin{array}{c}\text { O1s } \\
\text { (inside) }\end{array}$ & {$[(\mathrm{NEMM})(\mathrm{MOE})][\mathrm{FAP}]$} & {$[\mathbf{B M P}][\mathbf{F A P}]$} & {$[\mathrm{BMP}]\left[\mathbf{N T f}_{2}\right]$} \\
\hline $40^{\circ} \mathrm{C}$ & $\begin{array}{l}531.6(2.9) \text { eV } 68 \% \\
529.8(1.5) \text { eV } 32 \%\end{array}$ & $\begin{array}{l}531.7 \text { (2.7) eV 62\% } \\
529.9 \text { (1.6) eV 38\% }\end{array}$ & $\begin{array}{l}532.8(1.8) \text { eV } 57 \% \\
531.2(2.1) \text { eV } 25 \% \\
529.8(1.4) \text { eV } 18 \% \\
\end{array}$ \\
\hline $100^{\circ} \mathrm{C}$ & $\begin{array}{l}532.4(2.9) \text { eV } 62 \% \\
530.0(1.8) \text { eV } 38 \%\end{array}$ & $\begin{array}{l}531.4 \text { (3.1) eV 75\% } \\
529.7(1.4) \mathrm{eV} 25 \% \\
\end{array}$ & $532.8(1.8) \mathrm{eV}$ \\
\hline $\begin{array}{c}\text { O1s } \\
\text { (outside) }\end{array}$ & {$[(\mathrm{NEMM})(\mathrm{MOE})][\mathrm{FAP}]$} & {$[\mathbf{B M P}][\mathbf{F A P}]$} & {$[\mathrm{BMP}]\left[\mathrm{NTf}_{2}\right]$} \\
\hline $40^{\circ} \mathrm{C}$ & $\begin{array}{l}532.3(2.3) \text { eV } 60 \% \\
530.1(1.8) \text { eV } 40 \%\end{array}$ & $\begin{array}{l}531.9(2.3) \text { eV 55\% } \\
529.9(1.7) \text { eV } 45 \%\end{array}$ & $\begin{array}{l}532.7(2.2) \mathrm{eV} \text { 66\% } \\
530.1(1.9) \mathrm{eV} 34 \%\end{array}$ \\
\hline $100^{\circ} \mathrm{C}$ & $\begin{array}{l}532.2(2.8) \text { eV } 60 \% \\
530.0(1.8) \text { eV } 40 \%\end{array}$ & $\begin{array}{l}531.9(2.8) \text { eV } 68 \% \\
529.9(1.6) \text { eV } 32 \%\end{array}$ & $\begin{array}{l}532.8(1.9) \text { eV } 90 \% \\
530.5(2.1) \text { eV } 10 \%\end{array}$ \\
\hline
\end{tabular}


Table 4. P2p photoelectron band. FWHM is given in brackets.

P2p (inside) [(NEMM)(MOE)][FAP] [BMP][FAP] [BMP][NTf $\left.\mathbf{f}_{2}\right]$ 
Table 5. S2p photoelectron band. FWHM is given in brackets.

S2p

(inside) [(NEMM)(MOE)][FAP $]$

[BMP][FAP]

[BMP][NTf $\left.\mathbf{N}_{2}\right]$

$40^{\circ} \mathrm{C}$

$169.3(2.8) \mathrm{eV}$

$169.4(2.4) \mathrm{eV}$

$169.2(2.5) \mathrm{eV}$

$100^{\circ} \mathrm{C}$

$169.6(2.5) \mathrm{eV}$

Undetectable

$169.2(2.8) \mathrm{eV}$ 